\title{
Energy Recovery in SWRO Desalination: Current Status and New Possibilities
}

\author{
Andrew James Schunke ${ }^{1}$, German Alberto Hernandez Herrera ${ }^{2 *}$, Lokesh Padhye ${ }^{1}$ and \\ Terri-Ann Berry ${ }^{2}$ \\ ${ }^{1}$ The University of Auckland, Auckland, New Zealand, ${ }^{2}$ Environmental Solutions Research Centre, Unitec Institute of \\ Technology, Auckland, New Zealand
}

OPEN ACCESS

Edited by:

Feni Agostinho,

Paulista University, Brazil

Reviewed by:

Maddalena Ripa

Autonomous University of

Barcelona, Spain

Fábio Sevegnani,

Paulista University, Brazil

*Correspondence:

German Alberto Hernandez Herrera hhernandez@unitec.ac.nz

Specialty section:

This article was submitted to Urban Resource Management,

a section of the journal

Frontiers in Sustainable Cities

Received: 20 November 2019

Accepted: 11 March 2020

Published: 03 April 2020

Citation:

Schunke AJ, Hernandez Herrera GA,

Padhye $L$ and Berry T-A (2020) Energy Recovery in SWRO Desalination:

Current Status and New Possibilities.

Front. Sustain. Cities 2:9,

doi: 10.3389/frsc.2020.00009
Reverse osmosis $(\mathrm{RO})$ technology requires high energy input in order to extract freshwater from seawater. Improvements in RO technology have led to seawater RO (SWRO) becoming the dominant form of large scale desalination around the world. However, the specific energy consumption (SEC) of SWRO remains substantially higher than that for surface water treatment and indirect potable recycling, making SWRO less cost effective than other alternatives for producing potable water. Furthermore, where non-renewable energy sources are used to supply SWRO energy demand, higher levels of greenhouse gas are emitted compared with lower energy alternatives. The purpose of this paper is to review the $\mathrm{RO}$ process configurations currently available and their impact on reducing SWRO energy consumption. This paper highlights the main factors contributing to SWRO energy consumption and presents some of the commonly adopted approaches to reducing SEC in SWRO plants. The use of energy recovery devices (ERDs) in SWRO is explored and the relative effectiveness of the various types of ERDs in reducing SEC presented.

Keywords: desalination, energy recovery devices, RO process configurations, hybrid process configurations, specific energy consumption

\section{INTRODUCTION}

Population growth and urbanization of cities worldwide is placing ever-greater stress on existing water supplies. Climate change effects on rainfall patterns and drought in certain parts of the world has added further pressure to the problem of global water shortage. Around 4 billion people are affected by water shortage for at least 1 month every year, with this number predicted to increase in the coming decades (Mekonnen and Hoekstra, 2016).

Seawater desalination is increasingly relied upon as a means of producing sustainable drinking water supply for cities where existing freshwater supplies are limited. By 2016, there were 18,983 commercial-scale desalination plants supplying over 95 million $\mathrm{m}^{3}$ day $^{-1}$ to cities worldwide [Global Water Intelligence (GWI), 2016], with desalination projects increasing in number and size by $5-6 \%$ internationally since 2010 (Voutchkov, 2018). Reverse Osmosis (RO) is gaining prominence as a desalination technology, accounting for $65 \%$ of production capacity worldwide (Abdelkareem et al., 2018; Bhojwani et al., 2019). RO involves the application of external energy (typically high pressure pumping) to drive water through a semi-permeable membrane, from less dilute (feed) to more dilute (permeate) solution.

Seawater RO (SWRO) offers several advantages over other desalination methods including high efficiency and selectivity, easy control and scale-up, flexibility, and suitability for integrated 
applications (Ramato et al., 2019; Urrea et al., 2019). However, SWRO desalination requires significantly more energy than alternative forms of potable water treatment. While conventional surface water treatment requires $0.2-0.4 \mathrm{kWh} \mathrm{m}^{-3}$, and indirect potable reuse (IPR) requires $1.5-2.0 \mathrm{kWh} \mathrm{m}^{-3}$, SWRO desalination needs between 3.5 and $4.5 \mathrm{kWh} \mathrm{m}^{-3}$ to produce product water (Kim and Hong, 2018; Voutchkov, 2018). Most of the energy consumed by conventional desalination uses fossil fuels, therefore contributing to greenhouse gas emissions. In 2015, Australia emitted $1,193 \mathrm{kt} \mathrm{CO}_{2} \mathrm{e}$ from desalination processes (Heihsel et al., 2019), which represents $<1 \%$ of total emissions from electricity. Various attempts to address these issues have included operational changes and the use of energy recovery devices (ERDs) (Park et al., 2020), improvements in membrane technology (Hailemariam et al., 2020), the use of integrated/hybrid membrane systems (Ang et al., 2015) and renewable energy sources (Shemer and Semiat, 2017; Khan M. A. M. et al., 2018).

The metric Specific Energy Consumption (SEC) compares energy efficiency in SWRO plants which comprises (1) seawater intake, including low pressure pumps; (2) screening and pre-treatment; (3) RO system, including membranes and high pressure pumps (HPP) ( $65 \%$ of SEC); (4) permeate system, including post-treatment, storage and pumping to the distribution network; and (5) concentrate (brine) disposal. SEC can range between 3 and $6.7 \mathrm{kWh} \mathrm{m}^{-3}$, depending on feed conditions, product water requirements and plant efficiency (Zhou et al., 2017; Wang et al., 2019). HPP typically require between 55 and 70 bar pressure to increase feedwater pressure above osmotic pressure of seawater (Khan S. U. et al., 2018). The energy consumed by HPP has historically been a significant factor in the overall energy consumption and operational cost of SWRO desalination (Karabelas et al., 2018; Zarzo and Prats, 2018).

The overall aim of this article is to assess the applicability and energy considerations of a variety of process configurations which include hybrid systems. This article will further discuss the factors affecting SEC and focus on solutions involving the use of ERDs and RO process configurations, as well as the potential of hybrid configurations. Table 1 provides an overview of the various energy reduction methods discussed.

\section{ENERGY RECOVERY DEVICES}

The high pressure pumping required to overcome the osmotic pressure in saline feedwater results in a saline concentrate stream which is highly pressurized. ERDs are commonly used to recover this hydraulic energy and transfer it to the feed stream, reducing both the amount of energy otherwise required by the HPPs and the size of HPP required (Guirguis, 2011). The earliest ERDs used in SWRO plants were centrifugal-type devices such as the Francis Turbine, Pelton Wheel and Turbocharger (Urrea et al., 2019). These devices convert the hydraulic energy of the concentrate into mechanical energy to drive a piston or pump, which transfers hydraulic energy back into the feed.

Since around 2000, isobaric chamber ERDs have replaced centrifugal devices in most new SWRO plants. Isobaric ERDs transfer hydraulic energy from the concentrate directly into the feed, as the two streams come into direct contact (with minimal mixing). As a result of the single energy conversion, efficiency loss is reduced when compared with centrifugal ERDs. There are two main types of isobaric chamber: rotary-driven and piston-driven:

- Rotary-driven ERDs comprise a central rotor operating on a hydrodynamic bearing where the low pressure feed and high pressure concentrate are introduced. The rotor is filled with low pressure feed, sealed, then high pressure concentrate is introduced, pressurizing the low pressure feed, pushing it out toward the RO membrane skid. After the rotor is resealed, the resulting low pressure concentrate is displaced by incoming low pressure feed water and the process repeats. PX (Pressure Exchange) is the most widely used rotary ERD in modern SWRO plants, due to its compact size, durability, modular design, and efficiency (Farooque et al., 2004; Kadaj and Bosleman, 2018; Urrea et al., 2019).

- Piston-driven ERDs follow a similar process of hydraulic energy exchange, with the transfer of energy between concentrate and feed occurring inside hydraulic cylinders, with the alternating pressurization / depressurization process controlled by a switcher valves. Piston-driven ERDs are less compact and modular than PX devices and require higher capital outlay and maintenance due to the need for control actuators and valving (Guirguis, 2011).

ERD efficiency (change in feed pressure divided by change in concentrate pressure) for various ERDs has been found to be Turbine $75 \%$, Turbocharger $80 \%$, Pelton Wheel $85 \%$, while isobaric chambers are around 95-97\% (Kim et al., 2019; Urrea et al., 2019). SEC has been reported for SWRO plants where various ERDs are installed as: Francis Turbines $>6 \mathrm{kWh} \mathrm{m}^{-3}$, Pelton Wheels 3.5-5.9 $\mathrm{kWh} \mathrm{m}^{-3}$, piston-driven ERDs 3.5-4.6 $\mathrm{kWh} \mathrm{m}^{-3}$, and PX 3.0-5.3 $\mathrm{kWh} \mathrm{m}^{-3}$ (Kim et al., 2019; Urrea et al., 2019). The PX is most effective at recovery rates up to $50 \%$ (Urrea et al., 2019). Energy savings with ERDs can be in the range of $25-40 \%$ compared with standard SWRO systems (Peñate and García-Rodríguez, 2011).

Rotary driven ERDs such as the PX are generally the preferred device due to compactness and durability, and with efficiencies of 95-97\%, there appears to be limited scope for substantial further development in ERD technology.

\section{RO PROCESS CONFIGURATIONS}

Several process configurations of SWRO have been developed to achieve improvements in both energy efficiency and water quality.

Single pass RO (Figure 1A) is the conventional and most widely adopted configuration due to its simplicity, ease of operation, and comparatively low cost. Single pass RO produces permeate with a TDS (total dissolved solids) concentration between 300 and $500 \mathrm{mg} \mathrm{L}^{-1}$ and has a recovery rate of up to $50 \%$ (Kim and Hong, 2018). Where higher quality product water is required, additional RO pass may be required. However, ongoing 
TABLE 1 | (A) Partial Two Pass RO (B) Split Partial Single Pass (SSP) RO (C) Split Partial Second Pass (SPSP) RO.

\begin{tabular}{|c|c|c|c|c|c|}
\hline $\begin{array}{l}\text { Technology or } \\
\text { process }\end{array}$ & Advantages & Disadvantages & $\begin{array}{l}\text { SEC kWh m³ } \\
\text { (Total SWRO) }\end{array}$ & $\begin{array}{l}\text { Energy } \\
\text { reduction }(\%)^{*}\end{array}$ & References \\
\hline Francis turbines $^{a}$ & Common/proven application & Double energy conversion & $6.2-6.7$ & 0 & $\begin{array}{l}\text { Gude, 2018; Urrea et al., } \\
2019\end{array}$ \\
\hline Pelton wheel $^{a}$ & Common/proven application & Double energy conversion & $3.5-5.9$ & $27 \%$ & $\begin{array}{l}\text { Kim et al., 2019; Urrea et al., } \\
2019\end{array}$ \\
\hline Piston-ERDa & Single energy conversion & $\begin{array}{l}\text { Additional capital and maintenance } \\
\text { cost for control actuators and } \\
\text { valving; potential for slight increase } \\
\text { in feed salinity during pressure } \\
\text { exchange. }\end{array}$ & $3.5-4.6$ & $37 \%$ & $\begin{array}{l}\text { Guirguis, 2011; Zhou et al., } \\
\text { 2017; Urrea et al., } 2019\end{array}$ \\
\hline$P X^{a}$ & $\begin{array}{l}\text { Single energy conversion; } \\
\text { compact; durable; modular } \\
\text { design. }\end{array}$ & $\begin{array}{l}\text { Potential for slight increase in feed } \\
\text { salinity during pressure exchange }\end{array}$ & $3-5.3$ & $36 \%$ & $\begin{array}{l}\text { Farooque et al., 2004; } \\
\text { Guirguis, 2011; Kim et al., } \\
\text { 2019; Urrea et al., } 2019\end{array}$ \\
\hline Single pass $\mathrm{RO}^{a}$ & $\begin{array}{l}\text { Conventional; easier to } \\
\text { operate; recovery rate up to } \\
50 \% \text {. }\end{array}$ & $\begin{array}{l}\text { Standard permeate quality (TDS } \\
300-500 \mathrm{mg} \mathrm{L}^{-1} \text { ) }\end{array}$ & $3.9-4.5$ & $35 \%$ & $\begin{array}{l}\text { Kim and Hong, 2018; Kim } \\
\text { et al., } 2019\end{array}$ \\
\hline Two pass $\mathrm{RO}^{\mathrm{a}}$ & $\begin{array}{l}\text { Improved permeate quality } \\
\text { (TDS 100-200 mg L-1) }\end{array}$ & $\begin{array}{l}\text { Increased energy and chemical } \\
\text { usage }\end{array}$ & $4.0-4.8$ & $32 \%$ & $\begin{array}{l}\text { Efraty, 2012; Peñate and } \\
\text { García-Rodríguez, } 2012 ; \\
\text { Ghaffour et al., } 2015\end{array}$ \\
\hline Partial two pass $\mathrm{RO}^{a}$ & $\begin{array}{l}\text { Improved permeate quality } \\
\text { (TDS 100-200 } \mathrm{mg} \mathrm{L}^{-1} \text { ) }\end{array}$ & $\begin{array}{l}\text { Increased energy and chemical } \\
\text { usage }\end{array}$ & $4-4.6$ & $33 \%$ & $\begin{array}{l}\text { Du et al., 2015; Kim and } \\
\text { Hong, } 2018\end{array}$ \\
\hline $\begin{array}{l}\text { Split Partial Single } \\
\text { Pass RO }(\mathrm{SSP})^{3}\end{array}$ & $\begin{array}{l}\text { Lower capital cost than two } \\
\text { pass }\end{array}$ & $\begin{array}{l}\text { Slight reduction on TDS from single } \\
\text { pass }\end{array}$ & $\mathrm{N} / \mathrm{A}$ & & $\begin{array}{l}\text { Warsinger et al., 2016; } \\
\text { Werber et al., } 2017\end{array}$ \\
\hline $\begin{array}{l}\text { Split Partial Second } \\
\text { Pass RO (SPSP)a }\end{array}$ & $\begin{array}{l}\text { High energy efficiency for } \\
\text { improved permeate quality }\end{array}$ & Higher capital and operational cost & $3.6-3.8$ & $43 \%$ & $\begin{array}{l}\text { Hermony et al., 2014; Du } \\
\text { et al., } 2015\end{array}$ \\
\hline FO hybrids ${ }^{b, c}$ & $\begin{array}{l}\text { Passive transfer; reduced } \\
\text { fouling; potential energy } \\
\text { savings and higher recovery } \\
\text { rates. }\end{array}$ & $\begin{array}{l}\text { Not commercially proven; highly } \\
\text { concentrated draw solution; high } \\
\text { membrane cost. }\end{array}$ & $\mathrm{N} / \mathrm{A}$ & & $\begin{array}{l}\text { Valladares Linares et al., } \\
\text { 2014; Altaee et al., 2018; } \\
\text { Awad et al., } 2019\end{array}$ \\
\hline PRO hybrids ${ }^{b, c}$ & $\begin{array}{l}\text { Potential to reduce energy } \\
\text { consumption and capital cost, } \\
\text { and increase recovery rates; } \\
\text { reduced salinity in } \\
\text { concentrate at outfall. }\end{array}$ & $\begin{array}{l}\text { Not commercially proven; } \\
\text { susceptible to fouling; requires } \\
\text { pre-treatment. Reliance on } \\
\text { co-location with dilute waste } \\
\text { stream. }\end{array}$ & $\mathrm{N} / \mathrm{A}$ & & $\begin{array}{l}\text { Zhang et al., 2014; Li, 2017; } \\
\text { Altaee et al., 2018; Wan and } \\
\text { Chung, 2018; Wang et al., } \\
2019\end{array}$ \\
\hline
\end{tabular}

${ }^{a}$ Commercial implementation, b ${ }^{b}$ Pilot phase, ${ }^{c}$ Modeling only.

${ }^{*}$ Energy reduction calculated with reference to SWRO with Francis Turbine, as FT is the oldest ERD technology and is generally the minimum standard on operational SWRO plants.

development of high-selective membranes may provide a more cost-effective solution to second pass.

Two pass RO involves a second RO unit in series which further treats permeate from the first to achieve improved quality. The additional energy (and cost) required to run the second RO makes this option generally unfeasible (Ghaffour et al., 2015).

Partial two pass RO (Figure 1B) involves feeding a portion of the first pass permeate through the second RO, while the remaining permeate bypasses the $\mathrm{RO}$, blending with the second pass permeate. The SEC is dependent on the ratio of permeate treated to permeate bypassed (Du et al., 2015).

Split partial RO configurations involve the extraction of permeate from different points along the membrane module. The front (upstream) elements produce higher quality permeate than rear (downstream) elements. Split partial RO therefore takes advantage of the lower salinity front permeate by directing it straight to the product stream, while the higher salinity rear permeate is treated further, either by diluting with seawater feed and recycling back through the RO unit (split partial single pass,
SSP, Figure 1C), or passing through a second RO system (split partial second pass, SPSP, Figure 1D).

SSP has been reported to reduce fouling and increase SWRO operation as well as decrease energy consumption and improve permeate quality by up to $15 \%$ compared with conventional single pass (Warsinger et al., 2016). With SPSP, the front permeate (lower TDS) bypasses the second-pass RO, while the rear permeate is fed into the second-pass, after which the two permeates are mixed. SPSP is reported to have the lowest SEC of the two pass configurations (Du et al., 2015).

Additional RO configurations involve passing RO concentrate through a second RO unit have been designed to achieve increased recovery and reduced concentrate volume, reducing plant size requirements. However, SEC is increased due to high pressure requirements of the second pass (Du et al., 2015).

Energy savings can also be gained by grouping the RO plant components into three banks (high pressure feed; membrane; energy recovery), referred to as "three center RO." This configuration has been adopted in large RO plants in Australia, 


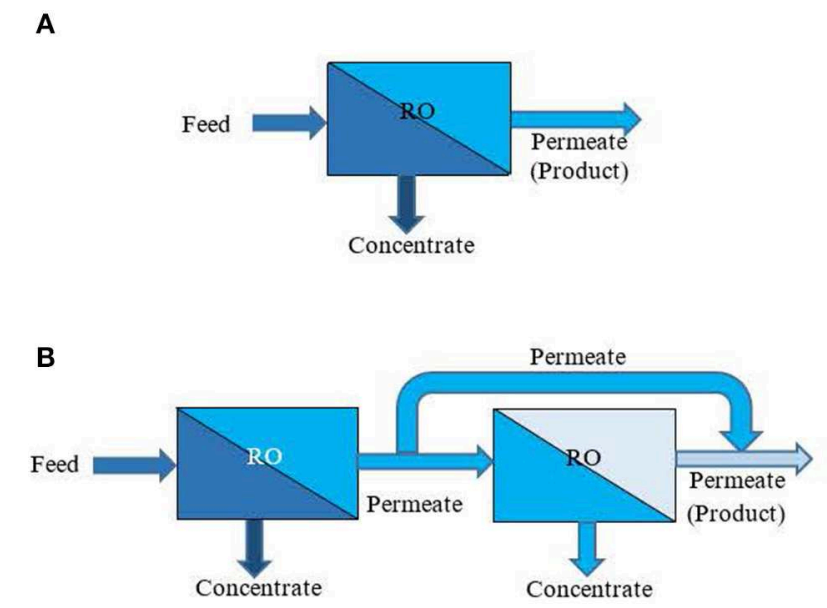

C

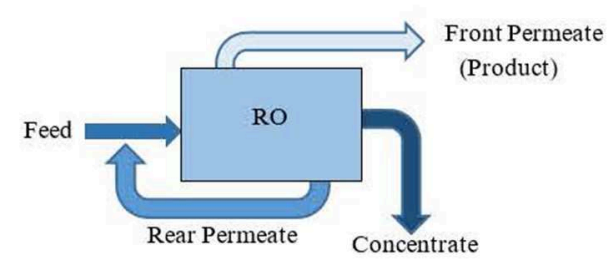

D

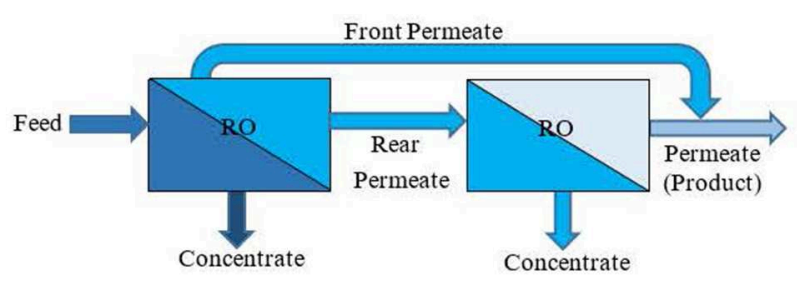

$\mathbf{E}$

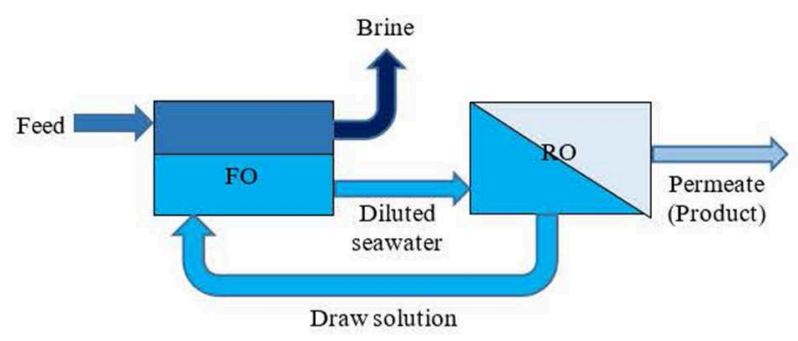

F

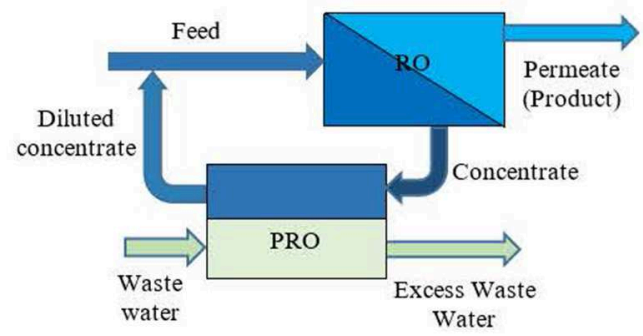

FIGURE 1 | (A) Single Pass RO (B) Partial Two Pass RO (C) Split Partial Single Pass (SSP) RO (D) Split Partial Second Pass (SPSP) RO (E) FO-RO (F) RO-PRO.

Israel and Middle East and provides reduced energy demand for diurnal flows (Voutchkov, 2018). However, three center design will not provide benefit where SWRO supplies only a small portion of total demand and therefore required to operate in batch mode (constant flow), as is the case for desalination plants utilized to supplement existing freshwater supplies.

SPSP is the preferred configuration where product quality requirements are higher, demanding second pass RO. Further investigation is required to verify the comparative benefits of three center RO.

\section{HYBRID PROCESS CONFIGURATIONS}

The integration of well-established RO technology with the emerging technologies of pressure retarded osmosis (PRO) and forward osmosis (FO) to optimize seawater desalination has been the focus of much research (Awad et al., 2019). PRO and FO both have potential applications in SWRO desalination, by introducing a more dilute waste stream into the process.

\section{Forward Osmosis}

FO involves the passive transfer of water molecules across a semi-permeable membrane from a more dilute feed to a less dilute draw solution. FO relies on the osmotic pressure gradient between two solutions, rather than introducing hydraulic pressure to drive water in the opposite direction. The diluted draw solution is treated further to recover freshwater from the draw solution. FO membranes when compared with RO operate under little to no hydraulic pressure, therefore reducing energy consumption. The absence of pumping results in reduced suspension of solids particles, which decreases the likelihood of fouling (Valladares Linares et al., 2014; Awad et al., 2019).

A major barrier to FO is the recovery of the highly concentrated draw solution and the associated energy requirement (Awad et al., 2019). The need for a high flux, high salt reject membrane to be developed also needs to be addressed (Valladares Linares et al., 2014). Conventional RO membranes are unsuitable for FO due to the high internal concentration polarization caused by the high concentration of draw solution, which can result in inorganic fouling (Zheng, 2017).

The draw solution must be carefully selected to ensure the concentration and osmotic pressure are higher than the feed, and such that freshwater can be readily recovered from the draw solution. Draw solution compounds range from metal salts to electromagnetic particles, however currently no suitable standard solution exists for different applications (Altaee et al., 2018).

Although the use of FO with SWRO desalination has yet to achieve commercial viability (Altaee et al., 2018; Awad et al., 2019), FO can be used as pre-treatment for SWRO desalination, with the potential to reduce energy consumption and increase recovery rates when compared with conventional SWRO processes. This FO-RO (FO followed by RO) process involves osmotic dilution by FO of a selected draw solution, with 
seawater as the feed, followed by a RO stage which is used as the draw solution recovery unit to produce freshwater and return regenerated draw solution back through (Figure 1E).

The highly selective FO membrane, combined with the draw solution recovery and regeneration process, maintains purity of the draw solution. This minimizes the degree of fouling of the RO membrane, which is subject to high hydraulic pressures and would otherwise suffer from flux decline and the resulting increase in pumping and energy (Altaee et al., 2018). Reduced fouling also leads to increased membrane life. Some drawbacks with FO pre-treatment include the additional capital cost for the extra membrane (FO) pumping and chemicals required when compared with conventional RO. Previous studies have shown that energy consumption is not favorable for seawater salinity below $35 \mathrm{~g} \mathrm{~L}^{-1}$, and FO pre-treatment may only reduce energy demands when inefficient or no ERDs are installed (Altaee et al., 2018).

FO may also be used in conjunction with RO desalination using seawater as the FO draw solution which is diluted by an introduced low concentration feed (e.g., river water or treated effluent). The diluted seawater is then pumped through RO to produce freshwater as per conventional SWRO desalination.

The main benefit of this FO-RO arrangement is that osmotic dilution of seawater means less hydraulic energy is required to drive the feed through the RO membrane. One of the main drawbacks is the availability of a low concentration FO feed, such as treated effluent, which may be achieved by co-location of desalination with a wastewater treatment plant.

FO has the potential to reduce pumping and energy requirements, however further research is necessary at pilot or operational scale to quantify and compare benefits.

\section{Pressure Retarded Osmosis}

PRO technology was first developed in Israel in the 1970's (Sakai et al., 2016), initially as an energy generation technology utilizing seawater, without RO desalination. The first operational PRO power plant commenced in Norway, however the plant was shut down in 2014 due to unsatisfactory performance (Altaee et al., 2017).

PRO can be integrated into the SWRO process as RO-PRO (RO followed by PRO, Figure 1F). Highly saline RO concentrate contains high osmotic energy. PRO utilizes a semi-permeable membrane to separate freshwater from a solvent via passive transfer of water. The increase in osmotic pressure on the draw side is harvested using an ERD. This energy can be used to offset energy required for high pressure pumping.

While several studies have demonstrated that RO-PRO is technically viable, practical application remains limited by performance and economic benefits yet to be validated (Wan and Chung, 2018; Wang et al., 2019). Mega-ton Water System in Japan is one of the only operational scale plants to date, where a 12-months trial reportedly showed the potential for $10 \%$ reduction in SEC (Kurihara and Takeuchi, 2018).

Several theoretical studies have demonstrated that RO-PRO can achieve energy savings over RO (Wan and Chung, 2016, 2018; Li, 2017) provided that plant recovery ratio is limited and the PRO unit has ample membrane area (Li, 2017; Wan and Chung, 2018). Energy recovery potential was also found to be proportional to feed salinity (Li, 2017). In addition to the potential cost savings associated with energy reduction, recycling a portion of the RO concentrate via PRO ("closed loop" RO$\mathrm{PRO}$ ) can substantially reduce capital cost due to reduction in seawater intake, pre-treatment and brine discharge units (Wan and Chung, 2018). Another advantage of RO-PRO is that RO concentrate is diluted back to seawater levels, reducing discharge impacts on marine ecology (Prante et al., 2014).

Several barriers to commercial viability of RO-PRO have been identified. PRO is susceptible to excessive fouling, requiring pre-treatment (Thelin et al., 2013; Zhang et al., 2014). Larger membrane areas are required to allow operation at lower recovery rates (Prante et al., 2014; Li, 2017). Finally, there is a reliance on availability of a dilute waste stream, usually requiring the desalination plant to be collocated with a municipal wastewater plant or other dilute waste stream (Wan and Chung, 2016).

PRO has the potential to harvest osmotic energy, reducing overall energy requirements, however further research is needed at pilot or operational scale to quantify and compare the benefits.

\section{CONCLUSION}

SWRO is currently the dominant form of commercial desalination treatment. However, the energy needed for high pressure pumping makes SWRO an expensive option for producing potable water when compared with common alternatives such as surface water treatment and IPR.

Major advances in the development of ERDs are such that they are now commonplace in SWRO plants, with the latest (isobaric) devices operating at around 97\% efficiency, enabling some plants to achieve SEC of $3 \mathrm{kWh} \mathrm{m}^{-3}$ (around double that of IPR and 10 times that of conventional surface water treatment). Although ERDs are proving essential to making SWRO more energy efficient and affordable, future developments in ERD technology will provide limited benefits in further reducing SWRO energy consumption.

Studies have shown that single pass RO generally required less energy than the various two pass RO options. A second pass $\mathrm{RO}$ is needed where product water quality standards are more stringent. For the two pass RO configurations, Spit Partial Second Pass RO was found to consume the least energy. It is noted however that these findings only suggest how SWRO plants can be optimized within the currently reported range of SEC.

RO hybrid configurations, whereby SWRO is integrated with pressure retarded osmosis (PRO) or forward osmosis (FO) technology, have the potential to make substantial reductions in overall energy requirement: FO by reducing the pump energy required for RO; PRO by harvesting and converting osmotic energy from the RO concentrate to offset RO pumping. While theoretical research suggests RO hybrid configurations can significantly reduce SEC, there remains a dearth of case studies at operational scale to support the commercial viability of RO hybrids. Barriers observed include PRO's susceptibility to fouling and scaling, the vast areas of 
membrane required, and the availability of a suitable dilute waste stream.

Further research and investigation is required, particularly at operational scale to validate the energy saving potential suggested by theoretical studies previously undertaken into FO and RO. Ongoing research into membrane performance and the potential to develop a high fouling resistant membrane are two ways in which RO-PRO hybrid could become a commercial reality.

\section{REFERENCES}

Abdelkareem, M. A., El Haj Assad, M., Sayed, E. T., and Soudan, B. (2018). Recent progress in the use of renewable energy sources to power water desalination plants. Desalination 435, 97-113. doi: 10.1016/j.desal.2017.11.018

Altaee, A., Alanezi, A. A., and Hawari, A. H. (2018). Emerging Technologies for Sustainable Desalination Handbook - Chapter 2: Forward Osmosis Feasibility and Potential Future Application for Desalination. (Oxford: ButterworthHeinemann) doi: 10.1016/B978-0-12-815818-0.00002-3

Altaee, A., Zaragoza, G., Drioli, E., and Zhou, J. (2017). Evaluation the potential and energy efficiency of dual stage pressure retarded osmosis process. Appl. Energy. 199, 359-369. doi: 10.1016/j.apenergy.2017.05.031

Ang, W. L., Mohammad, A. W., Hilal, N., and Leo, C. P. (2015). A review on the applicability of intergrated/hybrid membrane processes in water treatment and desalination plants. Desalination 363, 2-18. doi: 10.1016/j.desal.2014.03.008

Awad, A. M., Jalab, R., Minier-Matar, J., Adham, S., Nasser, S., and Judd, S. J. (2019). The status of forward osmosis technology implementation. Desalination 461, 10-21. doi: 10.1016/j.desal.2019.03.013

Bhojwani, S., Topolski, K., Mukherjee, R., Sengupta, D., and El-Halwagi, M. M. (2019). Technology review and data analysis for cost assessment of water treatment systems. Sci. Total Environ. 651, 2749-2761. doi: 10.1016/j.scitotenv.2018.09.363

Du, Y., Xie, L., Zhang, S., and Xu, Y. (2015). Optimization of reverse osmosis networks with split partial second pass design. Desalination 365, 365-380. doi: 10.1016/j.desal.2015.03.019

Efraty, A. (2012). Closed circuit desalination series no-6: conventional RO compared with the conceptually different new closed circuit desalination technology. Desalin. Water Treat. 41, 279-295. doi: 10.1080/19443994.2012.664741

Farooque, A. M., Jamaluddin, A. T. M., Al-Mobayed, A. S. A., and Qasim, A. H. (2004). Comparative study of various energy recovery devices use in SWRO process. TR.3807/EVP 02005. doi: 10.1016/j.desal.2007.06.004

Ghaffour, N., Bundschuh, J., Mahmoudi, H., and Goosen, M. F. A. (2015). Renewable energy-driven desalination technologies: a comprehensive review on challenges and potential applications of integrated systems. Desalination 356, 94-114. doi: 10.1016/j.desal.2014.10.024

Global Water Intelligence (GWI) (2016). IDA Desalination Yearbook 2016-2017, Water Desalination Report. Available online at: https://www.globalwaterintel. com/ (accessed August 25, 2019).

Gude, V. G. (2018). Sustainable Desalination Handbook-Plant Selection, Design and Implementation. Available online at: https://www.sciencedirect.com/ book/9780128092408/sustainable-desalination-handbook\#book-description (accessed July 28, 2019).

Guirguis, M. J. (2011). Energy Recovery Devices in Seawater Reverse Osmosis Desalination Plants with Emphasis on Efficiency and Economical Analysis of Isobaric versus Centrifugal Devices. Tampa, FL: University of South Florida.

Hailemariam, R. H., Woo, Y. C., Damtie, M. M., Kim, B. C., Park, K-D., Choi, J-S., (2020). Reverse osmosis membrane fabrication and modification technologies and future trends: a review. Adv. Coll. Interface Sci. 276:102100. doi: $10.1016 /$ j.cis.2019.102100

Heihsel, M., Lenzen, M., Malik, A., and Geschke, A. (2019). The caron footprint of desalination-an input-output analysis of seawater reverse osmosis desalination in Australia for 2005-2015. Desalination 454, 71-81. doi: 10.1016/j.desal.2018.12.008

\section{AUTHOR CONTRIBUTIONS}

AS and LP designed the work. AS and GH wrote the paper. AS and $\mathrm{T}-\mathrm{AB}$ contributed to the structure and editing of the paper.

\section{ACKNOWLEDGMENTS}

The authors would like to thank Chester Consultants Limited for their support throughout this project.

Hermony, A., Sutzkover-Gutman, I., Talmi, Y., and Fine, O. (2014). Palmachim Seawater desalination plant-seven years of expansions with uninterrupted operation together with process improvements. Desalin. Water Treat. 55, 2526-2535. doi: 10.1080/19443994.2014.940207

Kadaj, E., and Bosleman, R. (2018). "Energy recovery devices in membrane desalination processes," in Renewable Energy Powered Desalination Handbook: Application and Thermodynamics, 415-444. doi: 10.1016/B978-0-12-815244-7.00011-8

Karabelas, A. J., Koutsou, C. P., Kostoglou, M., and Sioutopoulos, D. C. (2018). Analysis of specific energy consumption in reverse osmosis desalination processes. Desalination 431, 15-21. doi: 10.1016/j.desal.2017.04.006

Khan, M. A. M., Rehman, S., and Al-Sulaiman, F. A. (2018). A hybrid renewable energy system as a potential energy source for water desalination using reverse osmosis: a review. Renew. Sustain. Energy Rev. 97, 456-477. doi: 10.1016/j.rser.2018.08.049

Khan, S. U., Khan, S. U., Danish, S. N., Orfi, J., Rana, U. A., and Haider, S. (2018). "Nuclear energy powered Seawater Desalination," in Renewable Energy Powered Desalination Handbook-Application and Thermodynamics, ed V. G. Gude (Oxford: Butterworth-Heinemann), 225-264. doi: 10.1016/B978-0-12-815244-7.00006-4

Kim, J., and Hong, S. (2018). A novel single-pass reverse osmosis configuration for high-purity water production and low energy consumption in seawater desalination. Desalination 429, 142-154. doi: 10.1016/j.desal.2017.12.026

Kim, J., Park, K., Yang, D. R., and Hong, S. (2019). A comprehensive review of energy consumption of seawater reverse osmosis desalination plants. Appl. Energy 254:113652. doi: 10.1016/j.apenergy.2019.113652

Kurihara, M., and Takeuchi, H. (2018). SWRO-PRO System in "Mega-ton Water System" for energy reduction and low environmental impact. Water 10, 48-63. doi: $10.3390 /$ w10010048

Li, M. (2017). Reducing specific energy consumption of seawater desalination: staged RO or RO-PRO? Desalination 422, 124-133. doi: 10.1016/j.desal.2017.08.023

Mekonnen, M. M., and Hoekstra, A. Y. (2016). Four billion people facing severe water scarcity. Sci. Adv. 2:e1500323. doi: 10.1126/sciadv.1500323

Park, K., Kim, J., Yang, D. R., and Hong, S. (2020). Towards a low-energy seawater reverse osmosis desalination plant: a review and theoretical analysis for future directions. J. Membrane Sci. 595:117607. doi: 10.1016/j.memsci.2019.117607

Peñate, B., and García-Rodríguez, L. (2011). Energy optimisation of existing SWRO (seawater reverse osmosis) plants with ERT (energy recovery turbines): technical and thermoeconomic assessment. Energy 36, 613-626. doi: 10.1016/j.energy.2010.09.056

Peñate, B., and García-Rodríguez, L. (2012). Current trends and future prospects in the design of seawater reverse osmosis desalination technology. Desalination 284, 1-8. doi: 10.1016/j.desal.2011.09.010

Prante, J. L., Ruskowitz, J. A., Childress, A. E., and Achilli, A. (2014). RO-PRO desalination: an integrated low-energy approach to seawater desalination. Appl. Energy 120, 104-114. doi: 10.1016/j.apenergy.2014.01.013

Ramato, A. T., Noviello, Y., Di Profio, G., Macedonio, F., Ali, A., Drioli, E., et al. (2019). Integrated membrane distillation-reverse electrodialysis system for energy efficient seawater desalination. Appl. Energy 253:113551. doi: 10.1016/j.apenergy.2019.113551

Sakai, H., Ueyama, T., Irie, M., Matsuyama, K., Tanioka, A., Saito, K., et al. (2016). Energy recovery by PRO in sea water desalination plant. Desalination 389, 52-57. doi: 10.1016/j.desal.2016.01.025 
Shemer, H., and Semiat, R. (2017). Sustainable RO desalinationenergy demand and environmental impact. Desalination 424, 10-16. doi: 10.1016/j.desal.2017.09.021

Thelin, W. R., Sivertsen, E., Holt, T., and Brekke, G. (2013). Natural organic matter fouling in pressure retarded osmosis. J. Membrane Sci. 438, 46-56. doi: 10.1016/j.memsci.2013.03.020

Urrea, S. A., Reyes, F. D., Suárez, B. P., and de la Fuente Bencomo, J. A., (2019). Technical review, evaluation and efficiency of energy recovery devices installed in the Canary Islands desalination plants. Desalination 450, 54-63. doi: 10.1016/j.desal.2018.07.013

Valladares Linares, R., Li, Z., Sarp, S., Bucs, S. S., Amy, G., and Vrouwenvelder, J. S. (2014). Forward osmosis niches in seawater desalination and wastewater reuse. Water Res. 66, 122-139. doi: 10.1016/j.watres.2014.08.021

Voutchkov, N. (2018). Energy use for membrane seawater desalination-current status and trends. Desalination 431, 2-14. doi: 10.1016/j.desal.2017.10.033

Wan, C. F., and Chung, T. S. (2016). Energy recovery by pressure retarded osmosis (PRO) in SWRO-PRO integrated processes. Appl. Energy 162, 687-698. doi: 10.1016/j.apenergy.2015.10.067

Wan, C. F., and Chung, T. S. (2018). Techno-economic evaluation of various $\mathrm{RO}+\mathrm{PRO}$ and RO+FO integrated processes. Appl. Energy 212, 1038-1050. doi: 10.1016/j.apenergy.2017.12.124

Wang, Q., Zhou, Z., Li, J., Tang, Q., and Hu, Y. (2019). Investigation of the reduced specific energy consumption of the RO-PRO hybrid system based on temperature-enhanced pressure retarded osmosis. J. Membrane Sci. 581, 439-452. doi: 10.1016/j.memsci.2019.03.079

Warsinger, D. M., Tow, E. W., Nayar, K. G., Maswadeh, L. A., and Lienhard, J. H. (2016). Energy efficiency of batch and semi-batch (CCRO) reverse osmosis desalination. Water Res. 106, 272-282. doi: 10.1016/j.watres.2016.09.029
Werber, J., Deshmukh, A., and Elimelech, M. (2017). Can batch or semibatch processes save energy in reverse-osmosis desalination? Desalination 402, 109-122. doi: 10.1016/j.desal.2016.09.028

Zarzo, D., and Prats, D. (2018). Desalination and energy consumption. What can we expect in the near future? Desalination 427, 1-9. doi: 10.1016/j.desal.2017.10.046

Zhang, M., Hou, D., She, Q., and Tang, C. Y. (2014). Gypsum scaling in pressure retarded osmosis Experiments, mechanisms and implications. Water Res. 48, 387-395. doi: 10.1016/j.watres.2013.09.051

Zheng, H. (2017). Solar Energy Desalination Technology-Chapter 1General Problems in Seawater Desalination (Amsterdam:Elsevier). doi: 10.1016/B978-0-12-805411-6.00001-4

Zhou, J., Wang, Y., Duan, Y., Tian, J., and Xu, S. (2017). Capacity flexibility evaluation of a reciprocating-switcher energy recovery device for SWRO desalination system. Desalination 416, 46-53. doi: 10.1016/j.desal.2017. 04.026

Conflict of Interest: The authors declare that the research was conducted in the absence of any commercial or financial relationships that could be construed as a potential conflict of interest.

Copyright (c) 2020 Schunke, Hernandez Herrera, Padhye and Berry. This is an openaccess article distributed under the terms of the Creative Commons Attribution License (CC BY). The use, distribution or reproduction in other forums is permitted, provided the original author(s) and the copyright owner(s) are credited and that the original publication in this journal is cited, in accordance with accepted academic practice. No use, distribution or reproduction is permitted which does not comply with these terms. 